\title{
Kegiatan Marketing Public Relations Terhadap Proses Pengambilan Keputusan Pembelian Apartemen Pada Generasi Milenial
}

\author{
${ }^{1}$ Gunawan Wiradharma, ${ }^{2}$ Khaerul Anam, ${ }^{3}$ Karina Pramita Ningrum \\ ${ }^{1,2}$ Universitas Terbuka dan, ${ }^{3}$ Universitas Pakuan \\ Email: gunawan.wiradharma@ecampus.ut.ac.id
}

\section{ARTICLE INFO ABSTRACT}

Keywords:

Marketing Public

Relations Activities,

Purchasing Decision

Making Process,

Apartments,

The Millennial Generation
The construction and sale of apartments in big cities have increased, leading to competition between companies that sell or lease apartment units. Marketing public relations activities are important in encouraging consumers to attract prospective customers' interest in the decision-making process. The purpose of this research is how the influence of marketing public relations activities on the decision-making process of buying apartments in the millennial generation in an apartment in Depok City in October 2019. This research's indicators are publications, media identity, events, news, speeches, participation in social activities, and sponsorship. The purchase decision-making process indicators are the introduction of needs, information seeking, alternative evaluations, purchasing decisions, and post-purchase behavior. This research method is a quantitative and explanatory survey of tenants/buyers of the period in October 2019. This study concludes that marketing public relations activities positively influence the purchase decision-making process to buy Apartment $X$ units in millennials.

\section{PENDAHULUAN}

Manusia dalam mempertahankan kelangsungan hidupnya memerlukan kebutuhan yang mendasar berupa tempat tinggal. Saat ini terdapat jenis tempat tinggal, yaitu hunian horizontal dan hunian vertikal. Dalam situasi saat ini manusia mempertimbangkan segi papan bukan hanya dari fungsi tempat tinggal sebagai tempat untuk berteduh, melainkan aspek bangunan yang kokoh, lingkungan yang aman dan nyaman serta mempertimbangkan aspek lokasi yang strategis.

Pembangunan hunian vertikal merupakan alternatif untuk melaksanakan kegiatan manusia di perkotaan karena keterbatasan lahan di kota sehingga pembangunan apartemen makin marak dikembangkan di Jakarta. Saat ini tinggal di hunian vertikal modern atau apartemen menjadi gaya hidup bagi seseorang yang tinggal di kota-kota besar.

Menurut wawancara singkat kepada beberapa orang yang tinggal di apartemen pada bulan Agustus 2019 di Apartemen Bandar Kemayoran, ada beberapa sejumlah alasan yang mendasar kepada seseorang untuk memilih tinggal di apartemen daripada di rumah bertanah atau tapak. Faktor utama yang menjadi pertimbangan seseorang dalam memilih apartemen adalah harganya lebih terjangkau daripada rumah bertanah atau tapak jika berlokasi di kota-kota besar. Alasan lainnya adalah lokasi apartemen yang dekat dengan tempat kerja atau tempat beraktivitas, seperti kampus yang biasanya dilengkapi dengan adanya fasilitas yang memadai, mulai dari adanya tempat kebugaran dan olahraga, pelayanan dan keamanan, mall, tempat kuliner, bahkan fasilitas leisure time. Selain itu, apartemen juga dapat dijadikan investasi atau bisnis berupa penyewaan jika tidak ditinggali langsung oleh penghuninya.

Melihat fenomena tersebut, pembangunan dan penjualan apartemen di kota-kota besar mengalami peningkatan bahkan terjadi persaingan antara perusahaan yang menjual atau menyewakan unit apartemen. Tingkat persaingan antara perusahaan hunian vertikal modern tersebut yang semakin tinggi dan ketat menyebabkan perusahaan pada umumnya berusaha untuk mempertahankan kelangsungan hidup. Syarat yang harus dipenuhi suatu perusahaan agar dapat sukses dalam persaingan 
adalah berusaha mencapai tujuan untuk menciptakan dan mempertahankan konsumen (Tjiptono, 2011:19).

Salah satu hunian vertikal modern yang ada di Depok adalah Apartemen X yang merupakan apartemen terkenal yang berada di Kota Depok. Apartemen ini merupakan hunian yang terdiri atas tempat tinggal yang dilengkapi dengan fasilitas untuk mengisi waktu luang lainnya, seperti olahraga, tempat bersantai atau berkumpul bersama rekan atau keluarga yang menarik, nyaman, modern. Apartemen X berlokasi strategis di Kota Depok yang berdekatan dengan Kampus Universitas Indonesia.

Generasi milenial yang tinggal di perkotaan, khususnya di kota besar seperti Jakarta, Bekasi, Depok, dan Tangerang memiliki gaya hidup kepemilikan tempat tinggal yang praktis dan menginginkan tempat tinggal yang dekat dengan tempat pendidikan atau kantor kerja. Keadaan ini dimanfaatkan oleh orang-orang yang berbisnis di bidang properti sebagai peluang bisnis. Mereka menawarkan tempat tinggal dengan konsep apartemen sebagai solusi permasalahan tempat tinggal masa pada saat ini untuk generasi milenial.

Saat ini bisnis di bidang properti makin ketat dalam persaingan. Persaingan ini tidak menimbulkan peluang dan tantangan. Salah satu tantangan yang dihadapi adalah bagaimana mendapatkan cara untuk memasarkan properti pada generasi milenial sebagai sasaran mereka dalam promosi apartemen. Oleh karena itu, komunikasi pemasaran diperlukan untuk menyampaikan informasi pemasaran properti. Penyampaian informasi tentang produk tersebut dapat dilakukan melalui berbagai bentuk program komunikasi pemasaran di antaranya advertising, sales promotions, personal selling, public relations, dan direct marketing (Kotler, 2012).

Marketing public relations merupakan salah satu bagian dari komunikasi pemasaran. Bagi perusahaan, marketing public relations masih sangat diperlukan meskipun perusahaan memiliki brand yang sudah sangat dikenal. Jika suatu brand yang sudah sangat dikenal tidak beriklan lagi, hal itu dapat berakibat pada brand value sehingga dapat menimbulkan kerugian bagi perusahaan. Dalam benak konsumen, marketing public relations merupakan sumber pengetahuan baru tentang brand dan berpotensi meningkatkan nilai tambah suatu brand.

Marketing public relations merupakan bagian penting dalam pemasaran produk dan salah satu cara khusus dalam memperkenalkan atau mempromosikan produk kepada konsumen. Saat ini marketing public relations sangat berperan dalam mendorong konsumen untuk melakukan pembelian pada generasi milenial. Marketing public relations oleh perusahaan digunakan untuk menarik minat konsumen untuk keputusan pembelian. Berdasarkan masalah di atas, perumusan masalah dalam penelitian ini adalah Apakah terdapat pengaruh marketing public relations terhadap keputusan membeli apartemen pada generasi milenial di Apartemen X periode Oktober 2019?

\section{KERANGKA TEORITIS}

\section{Marketing Public Relations}

Marketing public relations (MPR) merupakan sebuah jembatan yang diterapkan oleh organisasi yang secara langsung mencoba mendukung promosi perusahaan atau produk serta pembentukan citra. MPR awalnya lebih dikenal dengan publisitas, tetapi kini berfungsi lebih dari itu bahkan MPR memiliki peranan penting, yaitu mendukung peluncuran produk, membantu repositioning produk, memopulerkan kategori produk tertentu, memengaruhi kelompok sasaran tertentu, membela produk yang sedang dalam masalah, serta membangun citra perusahaan dan citra produk (Ali, 2017).

Marketing public relations adalah proses perencanaan dan pengevaluasian program-program yang mendorong pembelian dan kepuasan pelanggan melalui komunikasi yang berisi informasi yang dapat dipercaya dan dapat menciptakan kesan yang menggambarkan perusahaan dan produknya sesuai dengan kebutuhan pelanggan (Roslan dalam Ali, 2017). Dengan demikian, marketing public relations merupakan alat dan teknik public relations yang digunakan untuk menunjang sasaran penjualan suatu bisnis.

MPR dapat merupakan sebuah jawaban dari pertanyaan bagaimana tetap berjualan, tetapi tetap bisa memberikan citra positif. Dalam hal ini peran MPR dapat dijadikan suatu upaya penting bagi program utama perusahaan yang tengah berkompetisi di tengah persaingan seingga perusahaan akan mendapatkan citra baik dan mutual understanding. Di sinilah kegiatan MPR berlangsung dan kedua 
fungsi antara marketing dan pembentukan cita berjalan bersamaan. Kegiatan MPR merupakan kegiatan yang memadukan pelaksanaan program dan strategi pemasaran (marketing strategy implementation) dengan aktivitas program kerja PR (work program of public relations) (Ali, 2017).

Ada tujuh cara yang penting untuk menjadi dimensi dalam Kegiatan Marketing Public Relations (Kotler dan Keller dalam Primarni, 2009), yaitu pertama, publikasi (publication). Perusahaan mempercayakan perluasan produk berdasarkan dari publikasi materi untuk mempengaruhi dan menarik pembeli yang dituju. Yang termasuk di dalamnya membuat laporan tahunan, brosur, artikel, koran perusahaan, majalah, dan materi audiovisual. perlu membuat identitas yang bisa dikenal oleh masyarakat dengan mudah, misalnya, logo perusahaan, alat-alat tulis, brosur, tanda, formulir perusahaan, kartu nama, bangunan, seragam, dan peraturan pakaian.

Ketiga, event. Perusahaan bisa menarik perhatian mengenai produk baru ataupun kegiatan perusahaan dengan cara mengadakan acara khusus seperti wawancara, seminar, pameran, kompetisi, kontes dan ulang tahun agar terjangkau oleh masyarakat luas. Keempat, berita (news). Salah satu dari tugas utamanya public relations adalah untuk membuat atau menemukan acara yang sesuai dengan perusahaan, produknya, orang-orangnya atau pegawainya, dan membuat media tertarik untuk memuat berita press release dan hadir dalam press conference.

Kelima, Pidato. Semakin tinggi kebutuhan perusahaan untuk dapat menjawab setiap keperluan masyarakat dengan menjawab pertanyaan dari media atau memberikan pengarahan di asosiasi penjualan dan di meeting yang bertujuan untuk membicarakan penjualan membangun citra perusahaan. Keenam, peran serta dalam aktivitas sosial. Perusahaan bisa membangun image yang positif dengan cara menyumbang uang atau waktu dalam hal-hal yang positif. Ketujuh, sponsorship. Perusahaan bisa memasarkan barang mereka dengan mensponsori acara olahraga atau acara kebudayaan yang bermanfaat bagi kelangsungan perusahaannya.

\section{Proses Pengambilan Keputusan Pembelian}

Pengambilan keputusan pembelian merupakan suatu individu yang secara langsung terlibat dalam mendapatkan dan mempergunakan barang yang ditawarkan. Keputusan pembelian (purchase decision) adalah membeli merek yang paling disukai, tetapi dua faktor bisa berada antara niat pembelian dan keputusan pembelian. Faktor yang pertama adalah sikap orang lain. Faktor yang kedua adalah faktor situasional yang tidak diharapkan. Antara evaluasi alternatif dan keputusan pembelian terdapat minat membeli awal yang mengukur kecenderungan pelanggan untuk melakukan suatu tindakan tertentu terhadap produk secara keseluruhan (Amstrong, 2006).

Para ahli telah merumuskan proses pengambilan keputusan melalui model lima tahap yang meliputi (Amstrong, 2006), pertama pengenalan kebutuhan. Pengenalan kebutuhan merupakan proses pembelian yang dimulai saat pembeli mengenali masalah atau kebutuhan yang dipacu oleh rangsangan internal atau eksternal. Rangsangan internal berupa dorongan memenuhi rasa lapar, sedangkan rangsangan eksternal misalnya seseorang melewati toko kue dan melihat roti yang enak dan hangat sehingga terangsang rasa laparnya. Kedua, pencarian informasi. Konsumen yang memiliki kebutuhan terhadap sesuatu akan mencari informasi yang lebih banyak. Pada tingkat selanjutnya orang itu mungkin memasuki pencarian aktif informasi dengan mencari bahan bacaan, menelepon teman, dan mengunjungi toko untuk mempelajari produk-produk. Sumber informasi konsumen digolongkan ke dalam empat kelompok, yaitu Pribadi, Komersial, Publik, dan Pengalaman. Ketiga, evaluasi alternatif. Konsumen memiliki sikap yang beragam dalam memandang atribut yang relevan dan penting berdasarkan manfaat yang mereka cari dari suatu produk. Dalam memproses informasi merek kompetitif dan melakukan penilaian akhir dan tidak ada proses tunggal yang digunakan oleh konsumen dalam semua situasi pembelian. Keempat, keputusan pembelian. Dalam tahap evaluasi, konsumen akan membentuk preferensi terhadap merek-merek yang ada pada setiap pilihan. Tahap konsumen benar-benar membeli produk tersebut. Keputusan membeli konsumen adalah membeli merek yang paling disukai, tetapi dua faktor dapat muncul antara niat untuk membeli dan keputusan untuk membeli. Faktor pertama adalah sikap orang lain dan faktor kedua adalah situasi yang diharapkan. Kelima, perilaku pasca pembelian. Para pemasar harus memantau kepuasan pasca pembelian, tindakan pasca pembelian, dan pemakaian produk pasca pembelian yang tujuan utamanya adalah agar konsumen melakukan pembelian ulang. 


\section{Generasi Milenial}

Generasi milenial (Millenial Generation) biasa disebut juga sebagai generasi modern. Generasi milenial merupakan generasi modern yang hidup di pergantian milenium. Secara bersamaan di era ini teknologi digital mulai merasuk ke segala sendi-sandi kehidupan. Generasi milenial atau yang disebut juga generasi Y ini lahir sekitar tahun 1980 sampai 2000. Jadi, dapat dikatakan generasi milenial adalah generasi muda masa kini yang saat ini berusia sekitar 15-34 tahun. Kisaran usia tersebut sesuai dengan rata-rata usia mahasiswa yang sedang menempuh pendidikan di perguruan tinggi yaitu sekitar 19-34 tahun (Yuswohady, 2016).

Berdasarkan hasil penelitian dari Lancaster \& Stillman (2002), generasi Y dikenal dengan sebutan generasi millenial atau milenium. Penggunaan sebutan generasi Y dimulai pada bulan Agustus 1993 di editorial koran Amerika Serikat (Stillman, 2002). Generasi ini banyak menggunakan teknologi komunikasi instan seperti email, SMS, instant messaging, dan media sosial, seperti Facebook, Twitter, dan Instagram sehingga dengan kata lain generasi $\mathrm{Y}$ adalah generasi yang tumbuh pada era internet booming. Berdasarkan definisi tersebut dapat ditarik kesimpulan bahwa generasi milenial adalah generasi yang lahir di antara tahun 1980-2000 saat terjadi kemajuan teknologi yang pesat. Jika dilihat dari kelompok umur, generasi milenial merupakan generasi yang saat ini berusia kisaran 15-34 tahun.

\section{Model Penelitian}

Variabel Independen

\begin{tabular}{|l|}
\hline \multicolumn{1}{|c|}{ Variabel $(\mathbf{X})$} \\
Kegiatan Marketing \\
Public Relations \\
1. \\
2ublikasi \\
2. Identitas Media \\
3. Event \\
4. Berita \\
5. Peran Serta dalam \\
6. Aktivitas Sosial \\
\hline
\end{tabular}

Variabel Dependen

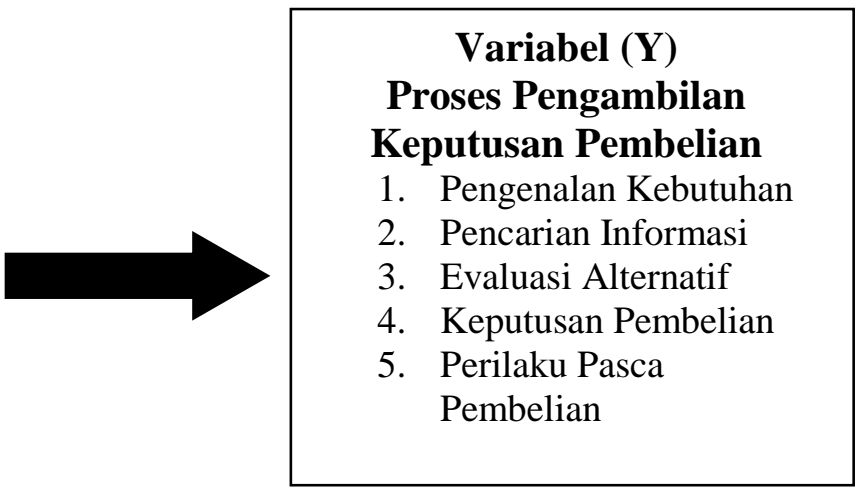

Gambar 1. Model Penelitian

\section{METODE PENELITIAN}

Pendekatan penelitian yang digunakan dalam penelitian ini adalah kuantitatif, dengan jenis penelitian survei karena menggunakan kuesioner sebagai alat penelitian. Populasi dalam penelitian ini adalah pembeli atau penyewa unit Apartemen $X$ yang melakukan transaksi beli atau sewa unit periode Oktober 2019. Apartemen X dipilih karena berdasarkan observasi yang dilakukan ke bagian Marketing diketahui bahwa penghuni apartemen ini sekitar $70 \%$ didominasi oleh mahasiswa yang kuliah di sekitar Depok. Karena tidak terdapat data yang spesifik mengenai jumlah penyewa dan pembeli apartemen, peneliti menjadikan penyewa dan pembeli apartemen pada bulan Oktober yang terdapat 60 orang yang melakukan transaksi sewa dan beli.

Sebelum membagikan kuesioner, peneliti melakukan uji pendahuluan (pilot test) kepada 12 responden untuk menguji ketepatan dan konsistensi instrumen penelitian. Dari uji pendahuluan, diperoleh validitas sebesar 0.758 (untuk variabel X) dan 0,853 (untuk variabel Y) dan reliabilitas diatas 0.600 sehingga riset ini dapat diandalkan. Data yang diperoleh kemudian diolah dengan piranti lunak Statistical Package for Social Science (SPSS) lalu dianalisis dengan teknik analisis deskriptif, regresi, dan tabulasi silang.

Hipotesis penelitian ini dapat dinyatakan sebagai berikut:

Ho --> Marketing public relations tidak berkorelasi terhadap keputusan pembelian apartemen pada penghuni Apartemen X.

Ha --> Marketing public relations berkorelasi positif terhadap keputusan pembelian apartemen pada penghuni Apartemen X. 
Operasionalisasi konsep dalam penelitian ini adalah sebagai berikut:

Tabel 1. Operasionalisasi Konsep

\begin{tabular}{|c|c|c|}
\hline Variabel & Dimensi & Indikator \\
\hline \multirow{6}{*}{$\begin{array}{c}\text { Kegiatan } \\
\text { Marketing } \\
\text { Public Relations } \\
\text { sebagai variabel } \\
\text { X atau } \\
\text { Independen } \\
\text { (Kotler dan } \\
\text { Keller dalam } \\
\text { Primarni, 2009: } \\
\text { 174) }\end{array}$} & 1. Publikasi & $\begin{array}{l}\text { a. Perusahaan memercayakan perluasan produk melalui publikasi } \\
\text { untuk memengaruhi minat pembeli yang dituju } \\
\text { b. Perusahaan memercayakan perluasan produk melalui publikasi } \\
\text { untuk menarik minat pembeli yang dituju }\end{array}$ \\
\hline & $\begin{array}{l}\text { 2. Identitas } \\
\text { Media }\end{array}$ & $\begin{array}{l}\text { a. Perusahaan telah membuat identitas (logo perusahaan) yang dapat } \\
\text { dikenal oleh masyarakat dengan mudah di media cetak. } \\
\text { b. Perusahaan telah membuat identitas (logo perusahaan) yang dapat } \\
\text { dikenal oleh masyarakat dengan mudah di media elektronik. } \\
\text { c. Perusahaan telah membuat identitas (logo perusahaan) yang dapat } \\
\text { dikenal oleh masyarakat dengan mudah di media baru. }\end{array}$ \\
\hline & 3. Event & $\begin{array}{l}\text { a. Perusahaan dapat menarik perhatian mengenai produk (beli) } \\
\text { dengan cara mengadakan acara khusus } \\
\text { b. Perusahaan dapat menarik perhatian mengenai produk (sewa) } \\
\text { dengan cara mengadakan acara khusus }\end{array}$ \\
\hline & 4. Berita & $\begin{array}{l}\text { a. Public relations memuat press release dari kegiatan yang } \\
\text { dilakukan. } \\
\text { b. Public relations memuat informasi produk di media. }\end{array}$ \\
\hline & $\begin{array}{l}\text { 5. Peran Serta } \\
\text { dalam } \\
\text { Aktivitas } \\
\text { Sosial }\end{array}$ & $\begin{array}{l}\text { a. Perusahaan membangun image positif dengan cara menyumbang } \\
\text { uang kepada masyarakat. } \\
\text { b. Perusahaan membangun image positif dengan cara mengadakan } \\
\text { kegiatan yang positif bagi masyarakat. }\end{array}$ \\
\hline & 6. Sponsor & $\begin{array}{l}\text { a. Perusahaan memasarkan produk dengan mensponsori acara olah } \\
\text { raga. } \\
\text { b. Perusahaan memasarkan produk dengan mensponsori acara } \\
\text { kebudayaan. }\end{array}$ \\
\hline \multirow{5}{*}{$\begin{array}{c}\text { Proses } \\
\text { Pengambilan } \\
\text { Keputusan } \\
\text { Pembelian } \\
\text { sebagai Variabel } \\
\text { Y atau dependen } \\
\text { (Kotler dan } \\
\text { Amstrong, 2006: } \\
\text { 179) }\end{array}$} & $\begin{array}{l}\text { 1. Pengenalan } \\
\text { kebutuhan }\end{array}$ & $\begin{array}{l}\text { a. Pembeli mengenali kebutuhan } \\
\text { b. Pembelian dipacu oleh rangsangan }\end{array}$ \\
\hline & $\begin{array}{l}\text { 2. Pencarian } \\
\text { Informasi }\end{array}$ & $\begin{array}{ll}\text { a. } & \text { Konsumen mencari informasi } \\
\text { b. } & \text { Konsumen aktif mencari informasi di media }\end{array}$ \\
\hline & $\begin{array}{l}\text { 3. Evaluasi } \\
\text { Alternatif }\end{array}$ & $\begin{array}{l}\text { a. Konsumen memiliki sikap beragam dalam memandang atribut } \\
\text { dalam produk } \\
\text { b. Konsumen mendapatkan manfaat yang mereka cari dari produk. }\end{array}$ \\
\hline & $\begin{array}{l}\text { 4. Keputusan } \\
\text { Pembelian }\end{array}$ & $\begin{array}{l}\text { a. Konsumen lebih memilih (preferensi) di dalam kumpulan pilihan. } \\
\text { b. Saat membeli, konsumen membeli sesuai merek yang paling } \\
\text { disukai. }\end{array}$ \\
\hline & $\begin{array}{l}\text { 5. Perilaku } \\
\text { Pasca } \\
\text { Pembelian }\end{array}$ & $\begin{array}{ll}\text { a. } & \text { Konsumen melakukan pembelian ulang } \\
\text { b. } & \text { Konsumen merasa puas terhadap produk yang dibeli. }\end{array}$ \\
\hline
\end{tabular}

\section{HASIL PENELITIAN DAN DISKUSI}

\section{Karakteristik Demografis Responden Penelitian}

Responden dalam penelitian ini terdiri atas jenis kelamin, usia, pekerjaan atau profesi, pendidikan, penghasilan, dan status unit apatemen. Berdasarkan hasil penelitian pengisian kuesioner para responden dapat diketahui karakteristik responden yang merupakan penghuni Apartemen X. Karakteristik responden penelitian ini didominasi oleh perempuan (55\%), usia 26-30 tahun (45\%), berprofesi sebagai pegawai swasta $(50 \%)$, pendidikan sarjana (S1) $(60 \%)$, penghasilan per bulan di atas dengan range $\mathrm{Rp} 15.000 .000$ hingga Rp 20.000 .000 (41.7\%), dan status kepemilikan apartemen adalah sewa (65\%).

Pada bagian ini, peneliti menampilkan analisis tabulasi silang yang meliputi jenis kelamin, usia, pekerjaan atau profesi, pendidikan, dan penghasilan per bulan. Berdasarkan hasil analisis tabulasi silang dapat diketahui karakteristik responden, yaitu karakteristik responden yang melakukan 
pembelian unit apartemen, dan karakteristik responden yang tidak melakukan pembelian unit apartemen.

Responden yang melakukan pembelian unit apartemen memiliki karaktersitik berikut, yaitu (1) jenis kelamin laki-laki, (2) berusia 21-25 tahun karena merasa tinggal diapartemen bersifat modern, simpel, mudah, nyaman, dan tersedia fasilitas yang lengkap, (3) berprofesi sebagai pegawai swasta, (4) berpendidikan sarjana (S1), dan (5) dan memiliki penghasilan antara Rp 15 juta hingga Rp 20 juta karena tinggal di apartemen harus membayar cicilan dan biaya bulanan.

Responden yang tidak melakukan pembelian unit apartemen memiliki karaktersitik berikut, yaitu (1) jenis kelamin laki-laki, (2) berusia 18-20 tahun karena usia tersebut merasa lebih enak tinggal bersama keluarga di rumah dan berusia > 31 tahun karena pada usia tersebut merasa lebih enak tinggal di rumah tanah mengingat usia tersebut sudah memiliki keluarga, (3) berprofesi sebagai pegawai negeri, (4) berpendidikan SMA dan Diploma, dan (5) dan memiliki penghasilan > Rp 20 juta karena lebih baik membeli rumah untuk investasi dan lebih baik untuk melakukan sosialisasi terhadap lingkungan sekitar.

\section{Analisis dan Pembahasan}

\section{Uji F}

Penelitian ini menggunakan analisis regresi dalam menentukan ada atau tidaknya korelasi antara variabel X (MPR) dan variabel Y (Keputusan Pembelian) dan seberapa besar pengaruh variabel $\mathrm{X}$ terhadap Y. Untuk hasil uji regresi dalam penelitian ini adalah sebagai berikut.

Tabel 2. Hasil Uji Regresi

ANOVA

\begin{tabular}{|rl|r|r|r|r|r|}
\hline \multicolumn{1}{|c|}{} & \multicolumn{1}{c|}{$\begin{array}{c}\text { Sum of } \\
\text { Sodel }\end{array}$} & & df & Mean Square & \multicolumn{1}{c|}{ F } & Sig. \\
\hline 1 & Regression & 9.871 & 1 & 9.871 & 151.474 & $.000^{\mathrm{a}}$ \\
& Residual & 3.779 & 58 & .065 & & \\
& Total & 13.650 & 59 & & & \\
\hline
\end{tabular}

Uji regresi variabel Kegiatan Marketing Public Relations terhadap Proses Pengambilan Keputusan Pembelian berdasarkan langkah-langkah berikut:

Kriteria Pengujian:

Jika Sig < 0.05, Ho ditolak dan

Jika Sig $>0.05$, Ho diterima

Berdasarkan hasil tabel 2 didapatkan hasil sig < 0.05, maka Ho ditolak dan Ha diterima. Hal ini berarti Kegiatan MPR berpengaruh secara signifikan terhadap Proses Pengambilan Keputusan Pembelian. Hasil uji $\mathrm{F}$ ini dapat dimaknai bahwa Kegiatan MPR dapat mempengaruhi Proses Pengambilan Keputusan Pembelian.

\section{Koefisien Determinasi}

Tabel 3. Koefisien Determinasi

Model Summary

\begin{tabular}{|l|r|r|r|r|}
\hline Model & \multicolumn{1}{|c|}{$\mathrm{R}$} & R Square & $\begin{array}{c}\text { Adjusted } \\
\text { R Square }\end{array}$ & $\begin{array}{c}\text { Std. Error of } \\
\text { the Estimate }\end{array}$ \\
\hline 1 & $.798^{\mathrm{a}}$ & .636 & .595 & 2.91341 \\
\hline
\end{tabular}

a. Predictors: (Constant), Sponsor, Peran Serta Dalam Aktivitas Sosial, Publikasi, Berita, Event, Identitas Media

Berdasarkan tabel 3, model summary dapat diketahui hasil dari R square yang disebut sebagai koefisien determinasi pengaruh Kegiatan MPR terhadap Proses Pengambilan Keputusan Pembelian unit apartemen dapat terlihat nilai sebesar 0.636. Hal itu berarti $63.6 \%(0.636 \times 100 \%=63.6 \%)$ yang berupa variabel Kegiatan MPR berpengaruh terhadap Proses Pengambilan Keputusan Pembelian unit apartemen. Sementara itu, sisanya sebesar $36.4 \%$ dipengaruhi faktor lain yang tidak dijadikan variabel 
dalam penelitian ini terhadap keputusan pembelian apartemen. Selain itu, berdasarkan hasil R square sebesar 0.636 dapat dikategorikan memiliki tingkat pengaruh kuat yang berada di range $0.60-0.799$.

\section{Uji T}

Tabel 4. Hasil Uji T

Coefficients $^{\mathrm{a}}$

\begin{tabular}{|c|c|c|c|c|c|c|}
\hline \multirow[b]{2}{*}{ Mod } & & \multicolumn{2}{|c|}{$\begin{array}{c}\text { Unstandardized } \\
\text { Coefficients }\end{array}$} & \multirow{2}{*}{$\begin{array}{c}\text { Standardized } \\
\text { Coefficients }\end{array}$} & \multirow[b]{2}{*}{$t$} & \multirow[b]{2}{*}{ Sig. } \\
\hline & & $\mathrm{B}$ & Std. Error & & & \\
\hline \multirow[t]{7}{*}{1} & (Constant) & 20.247 & 4.349 & & 4.656 & .000 \\
\hline & Publikasi & -.352 & .533 & -.066 & -.660 & .512 \\
\hline & Identitas Media & .119 & .423 & .042 & .282 & .779 \\
\hline & Event & .390 & .560 & .100 & .696 & .490 \\
\hline & Berita & 1.286 & .471 & .381 & 2.732 & .009 \\
\hline & $\begin{array}{l}\text { Peran Serta Dalam } \\
\text { Aktivitas Sosial }\end{array}$ & -.432 & .382 & -.104 & -1.130 & .264 \\
\hline & Sponsor & 1.453 & .457 & .439 & 3.181 & .002 \\
\hline
\end{tabular}

a. Dependent Variable: Keputusan Membeli

Variabel Kegiatan MPR berpengaruh terhadap Proses Pengambilan Keputusan Pembelian, Jika $-\mathrm{t}_{\text {tabel }}<\mathrm{t}_{\text {hitung }}<\mathrm{t}_{\text {tabel }}$ maka Ho diterima

Jika $<-\mathrm{t}_{\text {hitung }}<\mathrm{t}_{\text {tabel }}$ atau $<\mathrm{t}_{\text {hitung }}><\mathrm{t}_{\text {tabel }}$ maka Ho ditolak

Jika dilihat dengan derajat bebas (n-k)

$\mathrm{n}=$ Jumlah sampel dalam penelitian ini adalah 60 orang

$\mathrm{k}=$ Jumlah variabel yang digunakan dalam hal ini bernilai 2 sehingga

derajat bebasnya adalah 58 (60-2). Karena uji t yang dilakukan 2

arah, maka yang dibaca adalah $\mathrm{t}(1 / 2.0 .1)$ atau t 0.05 .

$\mathrm{t}_{\text {tabel }} \quad=-1,67155$

$\mathrm{t}_{\text {hitung }(\mathrm{X})}=10,321$

Karena thitung lebih besar dari t tabel, artinya hipotesis penelitian ini (Ha) diterima, Kegiatan Marketing Public Relations (X) berkorelasi positif terhadap Proses Pengambilan Keputusan Pembelian unit apartemen (Y).

\section{SIMPULAN}

Berdasarkan hasil penelitian, kesimpulan penelitian ini adalah Kegiatan Marketing Public Relations memiliki pengaruh yang positif terhadap Proses Pengambilan Keputusan Pembelian unit apartemen $\mathrm{X}$ pada generasi milenial.

\section{Saran}

Berdasarkan hasil penelitian ini, maka untuk penelitian selanjutnya penulis menyarankan untuk dapat meneliti kegiatan marketing public relations dan Proses Pengambilan Keputusan Pembelian dengan indikator yang berbeda.

\section{DAFTAR PUSTAKA}

[1] Ali, D. S. (2017). Marketing Public Relations: Di antara Penjualan dan Pencitraan. Jakarta: Deepublish.

[2] Amstrong, P. K. (2006). Prinsip-Prinsip Pemasaran. Jakarta: Erlangga.

[3] Cresswell, J. W. (1994). Research Design: Qualitative and Quantitative Approaches. Thousand Oaks: Sage Publications. 
[4] Kuspriyono, T. (2018). Pengaruh Iklan terhadap Keputusan Pembelian Apartemen Meikarta. Jurnal Humaniora Universitas Bina Sarana Informatika, 18(1).

[5] Neuman, W. (2007). Basic of Research Methods: Qualitative and Quantitative Approaches. Boston: Allyn and Bacon.

[6] Primarni, A. (2009). Introduction to Public Relations. Jakarta: Lentera Ilmu Aksara.

[7] S. Hidayatullah, d. (2018). Perilaku Generasi Milenial dalam Menggunakan Aplikasi Go-Food. Jurnal Manajemen dan Kewirausahaan, 6(2).

[8] Stillman, L. C. (2002). When Generations Collide: Who They Are. Why They Clash. How to Solve the Generational Puzzle at Work. New York: HarperCollins.

[9] Sugesti, H. (2017). Pengaruh Marketing Public Relations terhadap Keputusan Berkunjung ke Waterpark XYZ. Value Jurnal of Management and Business, 2(1).

[10] Tjiptono, F. (2011). Pemasaran Jasa. Malang: Bayumedia.

[11] Yuswohady. (2016). Millennial Trends 2016. Retrieved from http://www.yuswohady.com/2016 /01/1 7/millennial-trends-2016/ 